\title{
Effects of Loess Cavity on Soil Moisture Movement: Revealed by Soil Column and HYDRUS Model
}

\author{
Lybun Porn ${ }^{1,2}$, Baowen Yan ${ }^{1 *}$, Sovannaka Soun ${ }^{1,2}$, Sereyrorth Ouk ${ }^{1,2}$ \\ ${ }^{1}$ College of Water Resources and Architectural Engineering, Northwest A\&F University, Yangling, China \\ ${ }^{2}$ Faculty of Hydrology and Water Resources Engineering, Institute of Technology of Cambodia, Phnom Penh, Cambodia \\ Email: lybunp@nwafu.edu.cn, *yanbaowen@nwafu.edn.cn, suonsovannaka22@gmail.com,ouk_sereyrorth@yahoo.com
}

How to cite this paper: Porn, L., Yan, B.W., Soun, S. and Ouk, S. (2019) Effects of Loess Cavity on Soil Moisture Movement: Revealed by Soil Column and HYDRUS Model. Journal of Water Resource and Protection, 11, 371-394.

https://doi.org/10.4236/jwarp.2019.114022

Received: March 21, 2019

Accepted: April 5, 2019

Published: April 8, 2019

Copyright () 2019 by author(s) and Scientific Research Publishing Inc. This work is licensed under the Creative Commons Attribution International License (CC BY 4.0). http://creativecommons.org/licenses/by/4.0/

\begin{abstract}
The purpose of this study is to advance our current understanding of soil moisture storage in subsurface and water infiltration rate in loess soil. Therefore, a set of experiments was conducted on two soil columns filled with silty clay loam, with and without applying cavity technical method. For the soil column applied with loess cavity, the ponding infiltration was simulated using HYDRUS-2D/3D, version 2. $x$ and the simulated results were verified by those of observation. The results show that 1 ) the loess cavity significantly decreased the infiltration rates when the flux permeated through it (varying from 0.358 to $0.208 \mathrm{~cm} \cdot \mathrm{min}^{-1}$ ) as compared with no cavity soil column (varying from 0.408 to $0.241 \mathrm{~cm} \cdot \mathrm{min}^{-1}$ ); 2) similarly, the total cumulative infiltration and at the termination of wetting front advancement of soil column with cavity were $66 \mathrm{~cm}$ and $69 \mathrm{~cm}$ lower than that of no cavity soil column (76 and $78 \mathrm{~cm}$ ), respectively. Consequently, the soil moisture at the subsurface and surrounding the loess cavity was effectively ameliorated; 3 ) the model was capable of predicting water infiltration processes in the soil column with loess cavity, and the root mean square error of simulated water contents, wetting front advancements, cumulative infiltrations, and infiltration rates were from 0.22 to $3.63 \mathrm{~cm}^{3} \cdot \mathrm{cm}^{-3}, 1.6$ to $3.63 \mathrm{~cm}, 3.44 \mathrm{~cm}$, and $0.026 \mathrm{~cm} \cdot \mathrm{min}^{-1}$, respectively. Overall, the findings in this study indicate that loess cavity can effectively increase soil moisture storage at shallow surface and the HYDRUS-2D/3D model is capable of simulating and predicting scenarios to help achieve stable shallow soil surface with loess cavity.
\end{abstract}

\section{Keywords}

Loess Cavity, HYDRUS-2D/3D, Wetting Front Advancement, Infiltration Rate, Cumulative Infiltration, Water Content 


\section{Introduction}

The north-west Loess Plateau of China lies in arid and semi-arid regions. This region is characterized with thick loess deposits ranging from about 30 to $100 \mathrm{~m}$ or even $200 \mathrm{~m}$ [1]. The loess is mainly composed of fine-grained and yellow silty sediment, deposited by wind from north-west Gobi Desert over a long period of time [2]. Therefore, loess soil is vulnerably prone to water, wind, and water-wind erosion, and over $60 \%$ of the Loess Plateau has been subjected to soil loss with about 2000 to $2500 \mathrm{t} \cdot \mathrm{km}^{-2}$ of annual average soil loss [3]. The long agricultural history in ancient time [4] and the recent urbanization with great demand on daily usage and agricultural irrigation have jointly caused serious land degradation and water scarcity on the Loess Plateau [5]. As a result, water stress gradually becomes the most limited factor for rain-fed agriculture in this region, calling for better irrigation management to preserve water resources by producing more food with less water [6]. In this last decade, the effectiveness of vegetation restoration efforts in the Loess Plateau have been demonstrated by most of previous studies [7] [8] [9]. The water conservation efforts, involving in afforestation and/or vegetation restoration, terracing, increasing soil surface roughness to reduce the sediment yield from the hill slopes and delivery to rivers, and land degradation gradually decreased [10] [11]. However, these conservation efforts have been questioned for their negative consequences of excessive reduction of water resources (e.g., [12] [13] [14]).

Loess cavity, was firstly introduced by Dang, Li [15] and Yan, Dang [16]. This technical method, originally known as Cavity-Making Technology, was initially applied in farmland at Yangling, Northwest A\&F university for improving the soil moisture in subsurface. Based on the strong characteristics of the vertical structure of loess soil, the method of macro blasting and the drilling hole were applied to enlarge the bottom for creating a cavity with a single chamber diameter of about $40 \mathrm{~cm}$ and in the depth of $90-120 \mathrm{~cm}$ below soil surface. The upper soil of the cavity is loosened, which enhances the permeability of the upper layer, absorbs more precipitation into the soil, and reduces the runoff loss of the rainfall. The soil at the bottom of the cavity is compacted to form a relatively separate water storage layer, which can prevent deep seepage from precipitation and prevent evaporation of lower ground water pipes from rising, so as to achieve the purpose of seepage reduction, evaporation, and water storage. However, in the present study, the cavity created by explosion was replaced by a wire half-sphere basket of 22-cm diameter buried at the depth of $30 \mathrm{~cm}$ below the soil surface. Loess cavity can be one of the efficient techniques to increase infiltration, reduce evaporation, and help alleviate water shortage in northwest Loess area of China. [17]. There have been a couple of studies to apply cavity technique to investigate soil water interactions in porous mediums of arid-agriculture fields [15] [16] [18] [19]. They generally highlighted the effectiveness of this technique to preserve soil water in shallow layer, elevate soil water storage capacity and improve soil moisture in a dry season [15] [19]. However, field investigations will become 
very labor- and resource-costly if attempting to assess the long-term impacts of such loess cavity to local soil water utilization and recycling.

During the past several decades, there have been a large number of simulation models developed to evaluate water movement at the least cost [20]-[26]. In general, the most of the currently available modes are pressure-based with saturated flow equations [27] [28] [29]. Though, the pressure-base form models are more restrictive and closely related [30]. Amongst the most frequently known, the Richards' equation, which described the hydrodynamics of soil water movement [31], occupies a significant role in modern theoretical. Taking the advantages of complex initial and boundary conditions (BCs) based on finite differences or finite element methods with iterative implicit techniques, the Richards' equation can reflect the reality circumstances and heterogeneous textured soil [32] [33] (Rao, 2006).

HYDRUS-2D/3D version 2.x is one among the most widely used dynamics and physical model based on numerical solution of Richards' equation to simulate various hydrologic processes in one, two, or three dimensional variably saturated vadose zones using the finite element method [33] [34] [35]. Due to its adaptability in accommodating with different combinations of initial and boundary conditions, there are many researchers using HYDRUS-2D/3D model to investigate soil water movement in either laboratory or field experiments, or even build mathematical models [36]-[41]. Furthermore, HYDRUS-2D/3D model can also be used to trace water and solute movement and wetting fronts (WFs) in both homogenous and heterogeneous soils [42]. Overall, previous studies have proved the efficiency of HYDRUS-2D/3D model to simulate water infiltration and wetting front advancement at the field scale correctly [43]. However, no study has yet applied statistic model such as HYDRUS-2D/3D model to investigate the efficiency of loess cavity on improving the water soil porous media in the semi-arid Loess Plateau.

Therefore, the objectives of this study are 1) to capture patterns of soil water movement in two soil columns, and examine the influences of loess cavity in simulated soil column on infiltration process; 2 ) to evaluate soil water infiltration rate, water content and wetting front advancement based on the HYDRUS 2D/3D model in consideration of the ponding infiltration conditions. The remainder of this paper is organized as follows. Section 2 details the study materials and methods. Section 3 presents the main results of the experiments. Section 4 is about the interpretation and discussion of the results. Finally, Section 5 concludes the paper.

\section{Materials and Methods}

\subsection{Experimental Design}

First, confirm that you have the correct template for your paper size. This template has been tailored for output on the custom paper size $(21 \mathrm{~cm} \times 28.5 \mathrm{~cm})$.

In order to study the soil water movement with loess cavity in soil column, the 
experiment was conducted using a cavity-making technique at the college of architectural hydrology and water resources engineering, Northwest A\&F University, China. Two Plexiglas semi-circle containers of a height of $150 \mathrm{~cm}$ and 50 $\mathrm{cm}$ in diameter were used as the soil columns. To be a convenience for observing the wetting front advancements, the two plate sides of containers were gridded on lines in vertical and lateral direction ( $1 \mathrm{~cm}$ for each grid space). Soil sample, taken from Yangling, Shaanxi province, was silty clay loam soil. It was sieved through the filter of $4 \mathrm{~mm}$ in diameter, and filled into both soil columns. These soil columns were packed with three-layered soil at the thickness of 68,24 , and $28 \mathrm{~cm}$ for bottom, middle, and upper layer, respectively, and the quartz layers of $3 \mathrm{~cm}$ in thickness were laid on the upper surface in protecting soil erosion and texture damaged by applied water (Figure 1(a) \& Figure 1(b)). One of soil columns was chosen to bury a half-sphere basket at $30 \mathrm{~cm}$ below soil surface (Figure 1(a)) for creating a loess cavity. This half-sphere basket was made from wire, and had a diameter of $22 \mathrm{~cm}$. The time domain reflectometry (TDR) (Model CS605, Cambell Scientific) was utilized to measure the variation of volumetric water content in each soil layer. Its 20 moisture probes were horizontally installed at plate side of both containers in 5 lines (4 probes in each line) beneath soil surface at depth of $14 \mathrm{~cm}, 29 \mathrm{~cm}, 44 \mathrm{~cm}, 61 \mathrm{~cm}$, and $76 \mathrm{~cm}$ (Figure 2).

At the beginning of experiment, water pumping was not used but $42 \mathrm{~L}$ of water was simultaneously poured into both soil columns because of the consideration of the flash flood happening in the Loess Plateau. Preferential flows of both container side walls were barred by sealing them. Then, the variation of volumetric water content in each soil layer was measured using TDR every one hour; and the measurement of water front advancements was done every two hours. This process terminated when the advancement wetting front of both soil columns gradually decreased and nearly approached the stable phase in most part

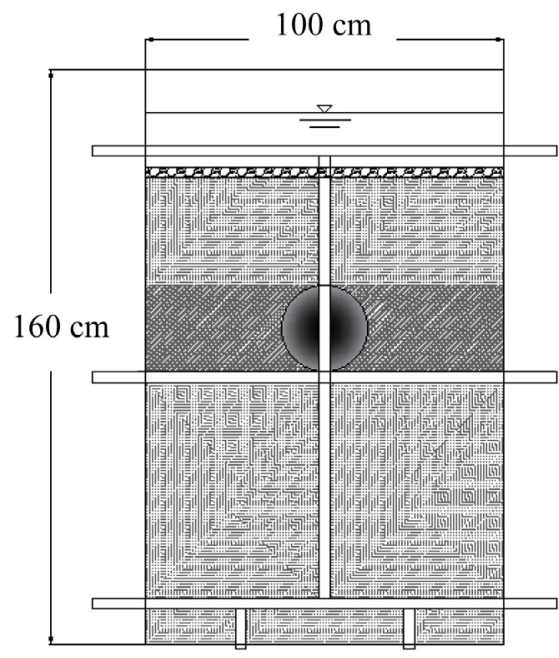

(a)

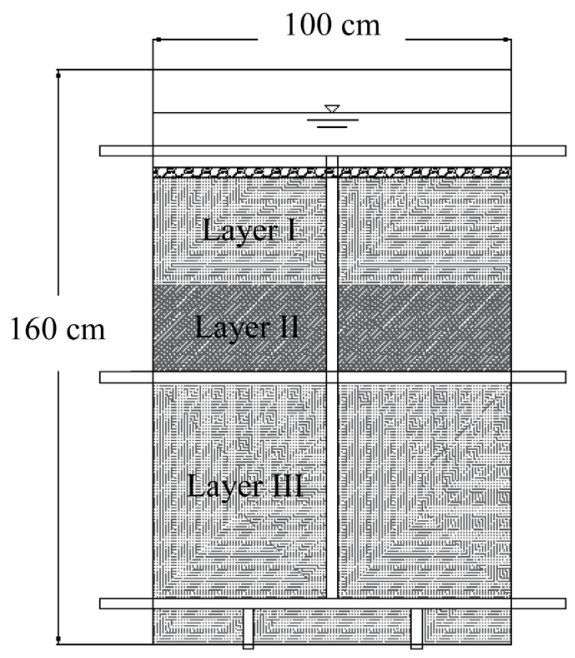

(b)

Figure 1. Scheme of the experimental setup represented: (a) Soil columns with loess cavity and (b) Soil column without loess cavity. 


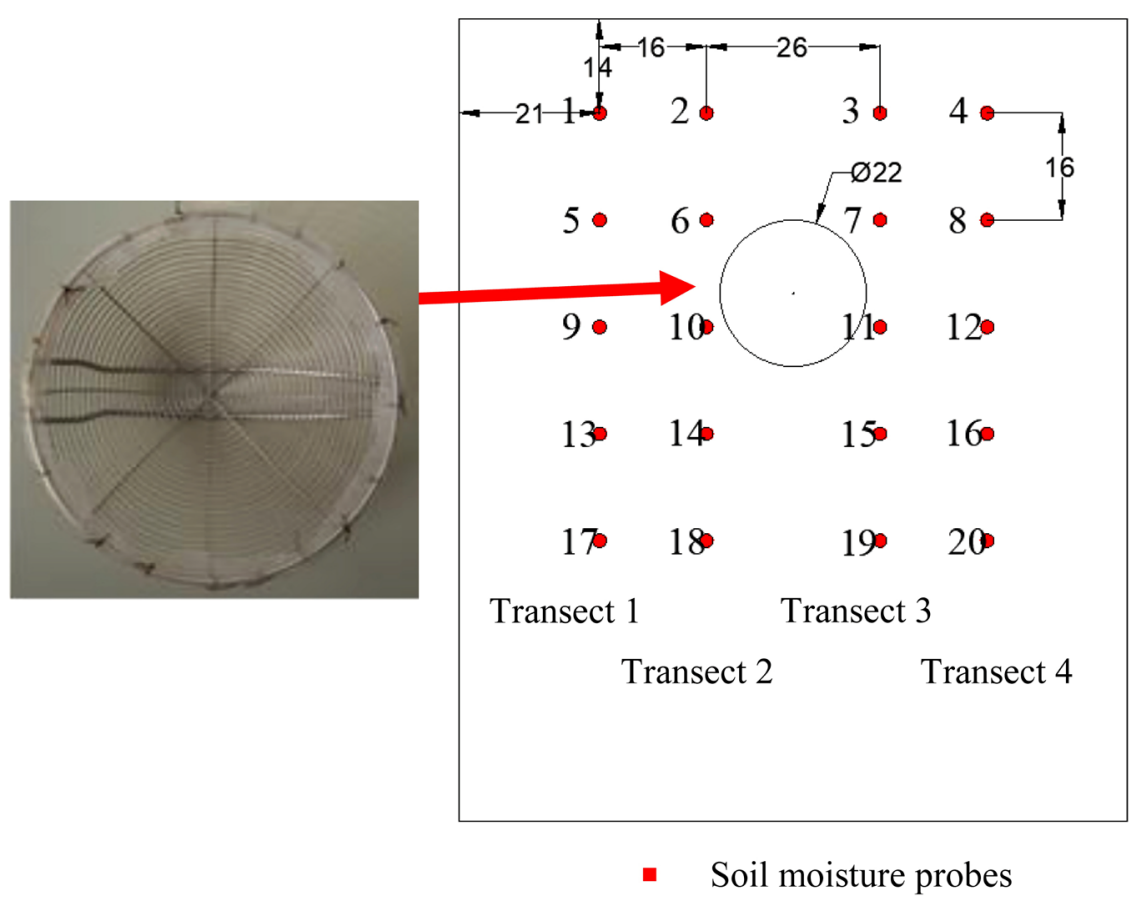

Figure 2. Scheme of the experimental plot displaying the position of TDR probes at each observation node and the vertical intersection 1, 2, 3, 4 .

of the last layer. This experimental study was conducted during $840 \mathrm{~min}$. During the experiment, the outside temperature was about $8^{\circ} \mathrm{C}$, consequently, the relevant evaporation of the current study was so small to take into account. Therefore, the effect of evaporation to the study results was neglected.

\subsection{HYDRUS 2D/3D Modeling}

The ponded infiltration was simulated using two-dimensional domain of HYDRUS-2D/3D software package [44]. This package is widely utilized for simulating $2 \mathrm{D} / 3 \mathrm{D}$ domain of water, solutes, and heat movement in variably saturation porous media with a multiple option of initial and boundary conditions and heterogeneous soil [45]. The governing flow equation described by the modified Richards equation in the HYDRUS 2D/3D code is applied for determining the water movement of axi-symmetrical isothermal Darcy flux in a variably saturated rigid isotropic porous media [46] [47]:

$$
\frac{\partial \theta}{\partial t}=\frac{\partial}{\partial x}\left(K_{x} \frac{\partial h}{\partial x}\right)+\frac{\partial}{\partial z}\left(K_{z} \frac{\partial h}{\partial z}\right)-\frac{\partial k}{\partial z}
$$

where $\theta$ is the volumetric water content (WC) $\left[\mathrm{cm}^{3} \cdot \mathrm{cm}^{-3}\right], h$ is the soil water pressure head $[\mathrm{cm}], K$ is the unsaturated hydraulic conductivity determined $\left[\mathrm{cm}^{3} \cdot \mathrm{h}^{-1}\right]$ by Equation (3), $x$ and $z$ are the lateral and vertical coordinate axis ( $z$ is positive downwards), respectively, and $t$ is time [h]. Note that Equation (1) is not include the root water uptake, since the process is approximately neglected at the time scale of this current study. And the porous medium is assumed to be isotropic. 
The Van Genuchten [48] modeling the soil water retention is described as:

$$
S_{e}=\left\{\begin{array}{cl}
\frac{\theta-\theta_{r}}{\theta_{s}-\theta_{r}}=\frac{1}{(1+(\alpha h))^{n m}} & \text { If } h \leq 0 \\
1 & \text { If } h>0
\end{array}\right.
$$

where $S_{e}$ is the effective saturation [-], $\theta_{s}$ and $\theta_{r}$ are the saturated and residual water content $\left[\mathrm{cm}^{3} \cdot \mathrm{cm}^{-3}\right]$, respectively, $\alpha$ is empirical coefficient $\left[\mathrm{cm}^{-1}\right]$ inversely related to the air-entry value (low for silty or clay texture and high for coarse soil), and $\mathrm{n}$ and $\mathrm{m}$ are constant empirical coefficients affecting the retention curve [-]. And $\mathrm{m}$ is determined by $m=1-1 / n$.

The hydraulic conductivity utilized the closed form equation of Van Genuchten [48], using the statistical pore-size index of Mualem [49] to combine with Equation (2), is implemented in HYDRUS-2D/3D as follows:

$$
K=\left\{\begin{array}{cl}
K_{s} \cdot S^{l}\left[\left(1-\left(1-S_{e}^{\frac{1}{m}}\right)^{m}\right)\right]^{2} & \text { If } h \leq 0 \\
K_{s} & \text { If } h>0
\end{array}\right.
$$

where $K_{s}$ is the saturated hydraulic conductivity $\left[\mathrm{cm}^{3} \cdot \mathrm{h}^{-1}\right], 0 \leq S_{e} \leq 1$, and $l$ is the tortuosity/connectivity coefficient [-] and generally has a value of 0.5 according to the analysis of a diversity of soils [50].

Simulations considering a $100 \times 100 \mathrm{~cm}$ profile, where a loess cavity having a diameter equal to $22 \mathrm{~cm}$ was put at $29 \mathrm{~cm}$ below the soil surface, was defined as a 2D transport domain. Galerkin finite element methods (FEM) is utilized by HYDRUS-2D/3D to solve Richards' equation [51]. The transport domain was discretized using and unstructured triangular FEM. The running model needs the soil hydraulic parameters, $\theta_{s}, \theta_{r}, K_{s}, n, \alpha, l$ and the initial soil water content as well.

\subsubsection{Spatial Discretization and Numerical Flow Domain}

The two-dimensional transport domain $(100 \times 100 \mathrm{~cm})$ considered for simulating water flow in soil loess column with applying cavity was vertical plan (Figure 3). The MESHGEN module of HYDRUS 2D/3D model was applied to generated the finite element mesh [46]. The non-uniformed FEM of smaller sizes were generated nearby the soil surface and gradually increasing with distance from the soil surface and where infiltration changes in the soil water content and corresponding pressure heads were most rapid. The finite element sizes were larger along the left and right boundaries, and the bottom boundary of the flow domain. The simulated domain with cavity was discretized into 3522 finite element nodes, 259 1D elements (Discretization of boundary and internal curves), and 6785 2D triangular finite elements with triangles considerably smaller around the cavity and then smoothly beginning larger and larger with distance from the cavity. The circle of the cavity was represented with 28 nodes. The observation nodes were designed into 4 vertical intersections, i.e., 21- , 37- , 63- , and 79-cm intersection, and 4 horizontal intersections at depth $14,30,46,62$, and $78 \mathrm{~cm}$. 


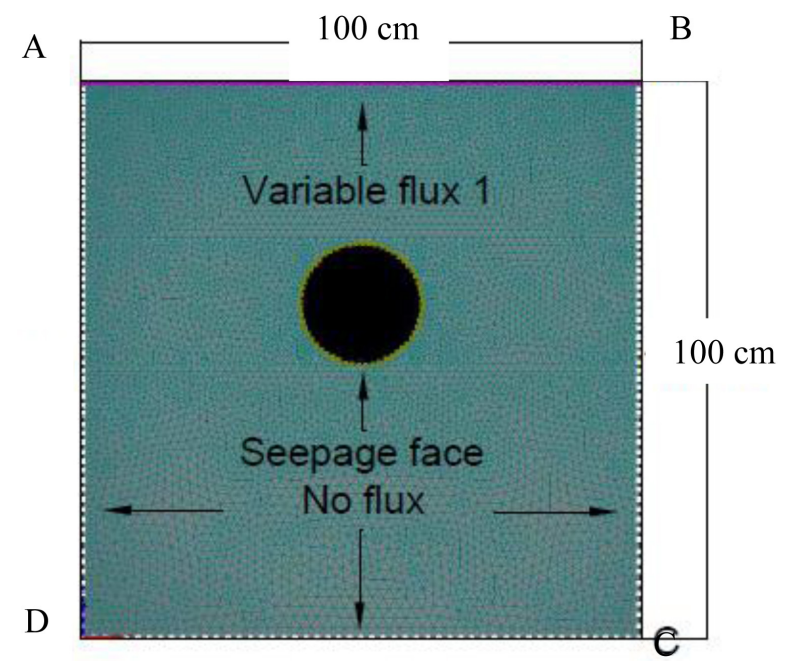

Figure 3. Scheme of the experimental plot displaying the position of TDR probes at each observation node and the vertical intersection 1, 2, 3, 4 .

Each cross line represented the observed probe which corresponded to the measured locations of soil contents (Figure 2).

\subsubsection{Defining Boundary Conditions}

The distributions of initial volumetric water content $\left(\theta_{r}\right)$ was assigned according to the results of interpolated water contents measured at every observation node probes of soil columns before starting the infiltration process. Since there was no probe measured water content at the surface and bottom of soil column with loess cavity, the measured values were extended to the top and bottom of the model domain, respectively. Figure 3 shows all details of the transport domain, in which the cavity loess are located. The soil profile was considered to be heterogeneous and differentiated depend on the measured soil bulk densities. The evaporation from bare soil and precipitation were neglected.

Figure 3 depicts the boundary conditions (BCs) of the transport domain with applying cavity. The upper boundary $(\mathrm{AB})$ was specified as a variable flux 1 which defined by flash flood. The time variable BCs were implemented and adjusted dynamically depending upon the water level in the surface $(A B)$ and conditions in the ponding domain. The $\mathrm{BCs}$ of both vertical sides ( $\mathrm{AD}$ and $\mathrm{BC}$ ) were subjected to no flux $\mathrm{BC}$, since there is no flow happened across these boundaries. The cavity was represented as a circle of $11 \mathrm{~cm}$ radius, located at $30 \mathrm{~cm}$ beneath the variable flux $1 \mathrm{BC}$, assigned a seepage face $\mathrm{BC}$. In this study, the water table was not considered, then there was no effect on the flow in the interest transport domain. Consequently, the bottom of the flow domain (CD) was subjected to a no-flux boundary condition since water infiltration is not reached the bottom for this experiment.

\subsubsection{Input Requirements and Validation of the Model}

Soil samples of two different soil columns were collected from three-layer soil along the vertical axis beneath the soil surface to $100-\mathrm{cm}$ depth to determine soil 
physical properties. They were collected using the metallic rings and measured the dry soil bulk density. The sedimentation method (pipette and hydrometer) was used to measure soil particle size. Table 1 demonstrates the soil hydraulic parameters and the van Genuchten simulated results of three soil layers of soil columns with and without loess cavity. Rosetta pedotransfer function was implemented to predicted these parameters from different soil layers by utilizing the measured results of soil particle size percentage and soil bulk densities [52]. The texture of soil profile $(0-120 \mathrm{~cm}$ depths $)$ is classified as silty clay loam for all with the bulk densities varying from 1.15 to $1.29 \mathrm{~g} \cdot \mathrm{cm}^{-3}$. The values of $K_{s}$ within $120 \mathrm{~cm}$ soil profile ranged from 0.741 to $1.376 \mathrm{~cm} \cdot \mathrm{h}^{-1}$, with an average bulk density of $1.043 \mathrm{~cm} \cdot \mathrm{h}^{-1}$. The predicted values of $\theta_{s}\left(=0.183-0.345 \mathrm{~cm}^{3} \cdot \mathrm{cm}^{-3}\right)$, $\theta_{r} \quad\left(=0.03 \mathrm{~cm}^{3} \cdot \mathrm{cm}^{-3}\right), \alpha\left(=0.0064-0.0065 \mathrm{~cm}^{-1}\right)$, and $n(=1.5819-1.5874)$ were estimated by fitting the van Genuchten.

Finally, to compare the goodness of simulated results of HYDRUS-2D/3D to the measured results by sensor probes, three criteria indices, i.e., the root mean square error (RMSE) and the normalized root mean square error (NRMSE) [53] and the Nash-Sutcliffe model efficiency coefficient (EF) [54], were used to reflect the efficiency of simulation. These indices were calculated according to Equations (4)-(6):

$$
\begin{gathered}
\text { RMSE }=\sqrt{\frac{\sum_{i=1}^{n}\left(P_{i}-O_{i}\right)^{2}}{n}} \\
\mathrm{NRMSE}=\sqrt{\frac{\sum_{i=1}^{n}\left(\mathrm{O}_{i}-P\right)_{i}^{2}}{n}} \\
\mathrm{EF}=1-\frac{\sum_{i=1}^{n}\left(O_{i}-P_{i}\right)^{2}}{\sum_{i=1}^{n}\left(O_{i}-\overline{O_{i}}\right)^{2}}
\end{gathered}
$$

where $P_{i}$ is the simulated value; $O_{i}$ is the observed values, $\bar{O}$ is the average of observed value, and $n$ is the number of observations. These criteria indices were calculated on the unsorted data, the observed/predicted values were being directly compared. The RMSE should be noticeably as close as possible to zero [55].

\section{Results}

\subsection{Analysis of Experimental Results}

\subsubsection{Soil Water Movement and Changes in Soil Storage}

Figures 4(a)-(g) showed the comparison of the wetting front advancements of soil columns with and without loess cavity during 14 hours of infiltration process. Due to the WFs drawn every two hours for both soil columns, thus, Figures 4(a)-(g) represented the wetting front advancement at 2, 4, 6, 8, 10, 12, and 14 hours. As expected, it was found that the WFs moved rapidly at the commencement of water application for both soil columns. Since the water of 29 litters was abruptly poured into that two soil columns, thus the wetting patterns 


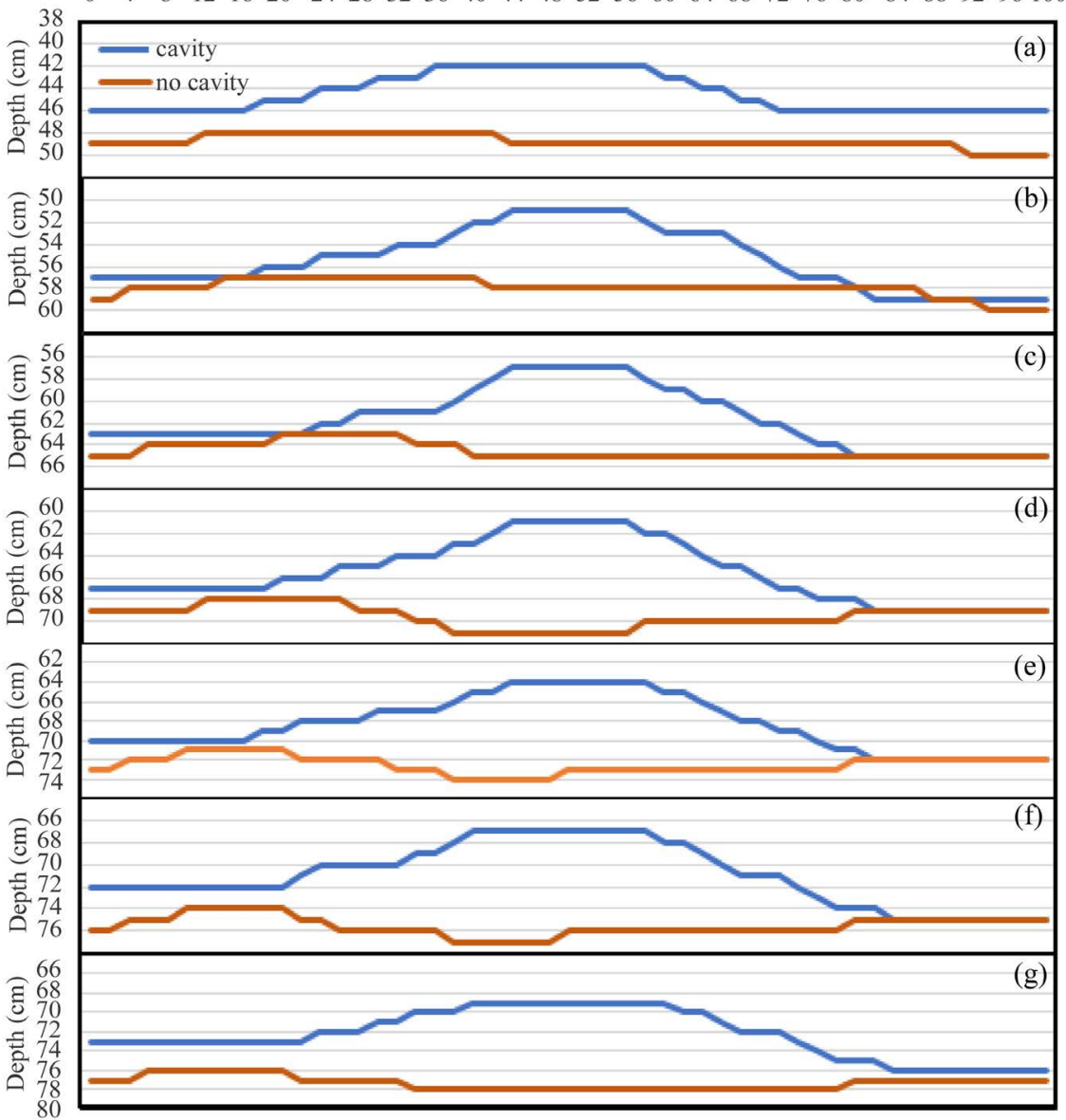

Figure 4. Comparison of the wetting front advancements with and without applying cavity in soil columns during 14 hours of infiltration process: (a) at 2 hours, (b) at 4 hours, (c) at 6 hours, (d) at 8 hours, (e) at 10 hours, (f) at 12 hours, and (g) at 14 hours.

in horizontal direction were promptly wetted and the wetted vertical direction was gradually permeated. The measurement of wetting front advancement at 2 , $4,6,8,10,12$, and 14 hours in soil column with cavity were $43,50,56,60,63,65$, and $66 \mathrm{~cm}$, respectively, while those of soil column without cavity were 49,58 , $65,71,74,75$, and $76 \mathrm{~cm}$, respectively (Figures $4(\mathrm{a})-(\mathrm{g})$ ). Noticeably, the WF of soil column without cavity started to move slower when it lasted for 10 hours and slightly changed until the end of experiment (Figures $4(\mathrm{e})$-(f)). Whereas, Figure 4(f) \& Figure 4(g) showed that the WF of cavity soil column just reached a little trend at 12 hours. Furthermore, as the evident of Figures 4(a)-(g), it was found that the movement of WFs in soil column with cavity were slower than those in soil column without cavity when water infiltrated through the loess cavity. Interestingly, the water distribution depths of soil column with loess cavity at the both sides were deeper than those at beneath of loess cavity. This means that the movement of soil water depth in loess cavity soil column was varied as a function of its distance to the loess cavity position. And the WFs of both columns were found to move closed to each other at the end of experiment (Figure 
$4(\mathrm{~g}))$.

Figure 5 demonstrates the observed infiltration rates and cumulative infiltrations in both soil columns with and without applying cavity. Obviously the soil column with cavity showed lower infiltration rate than which of without cavity. After the WFs reached 42 and $49 \mathrm{~cm}$ depths of soil columns with and without loess cavity, respectively, the infiltration rates of both columns decreased promptly from the maximum value of 0.358 to $0.208 \mathrm{~cm} \cdot \mathrm{min}^{-1}$ for soil column with cavity and 0.408 to $0.241 \mathrm{~cm} \cdot \mathrm{min}^{-1}$ for soil column without cavity after one hour of starting the experiment and they kept decreasing gradually after experiment have done 8 hours. These stages kept continuous until the end. The measured total cumulative infiltrations were 66 and $76 \mathrm{~cm}$ for soil column with and without cavity, respectively. This means more water has been held up and stored in caving layer. As the evident of Figure 9, the both cumulative infiltrations increased steadily through the whole infiltration process until finishing experiment. This can be stated as a linear function of times at the later infiltration stage.

\subsubsection{Spatial and Temporal Variations of Water Content in Vertical Transects}

The comparisons of water contents (WCs) with and without applying loess cavity in soil columns, of which the study was conducted during 14 hours shown in Figures 6(a)-(e) and Figures 7(a)-(e), at 14-, 30-, 46-, 62-, and 78-cm depths. The multiple curves denote the outputs at different times. Due to the installed probes in the symmetric phase, the probes in vertical $21-\mathrm{cm}$ and $37-\mathrm{cm}$ transects were chose for analysis section. As can be observed, the water contents of both soil columns were hastily increased in the first hour of experiment phase and

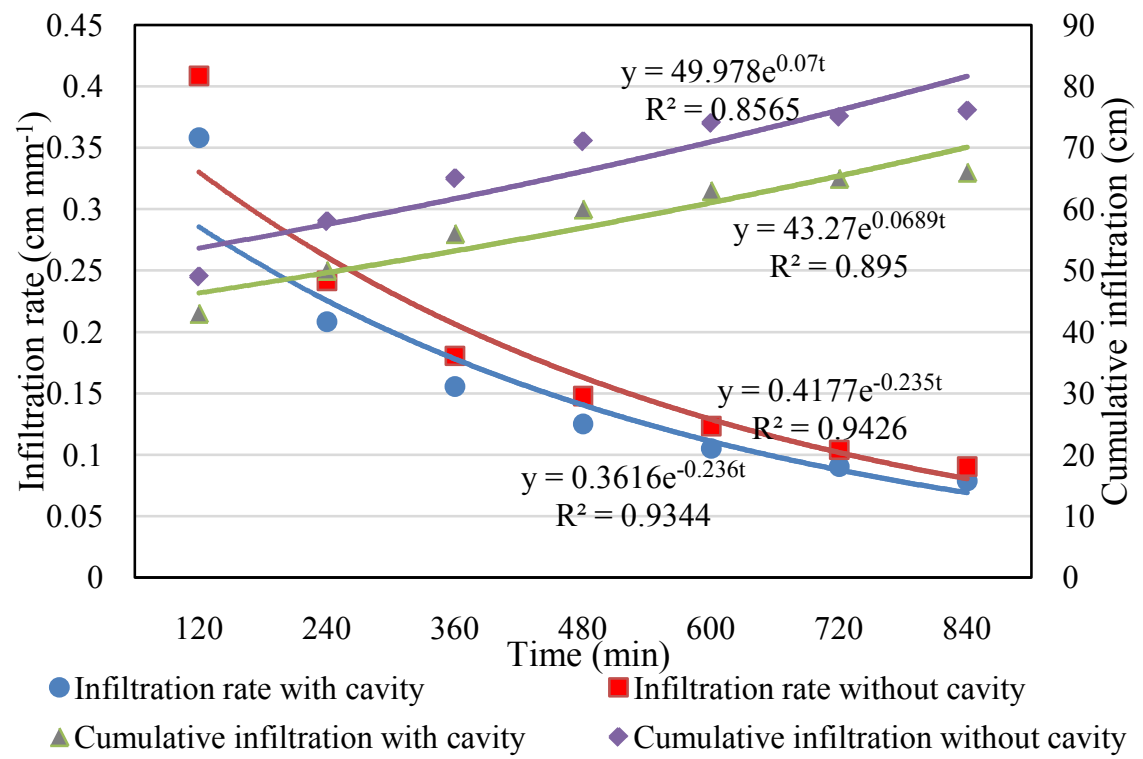

Figure 5. Comparison measured velocity $(\mathrm{cm} / \mathrm{h})$ of storm scenario during $14 \mathrm{~h}$ : vertical direction velocity of applied cavity making technology, without cavity making technology. 

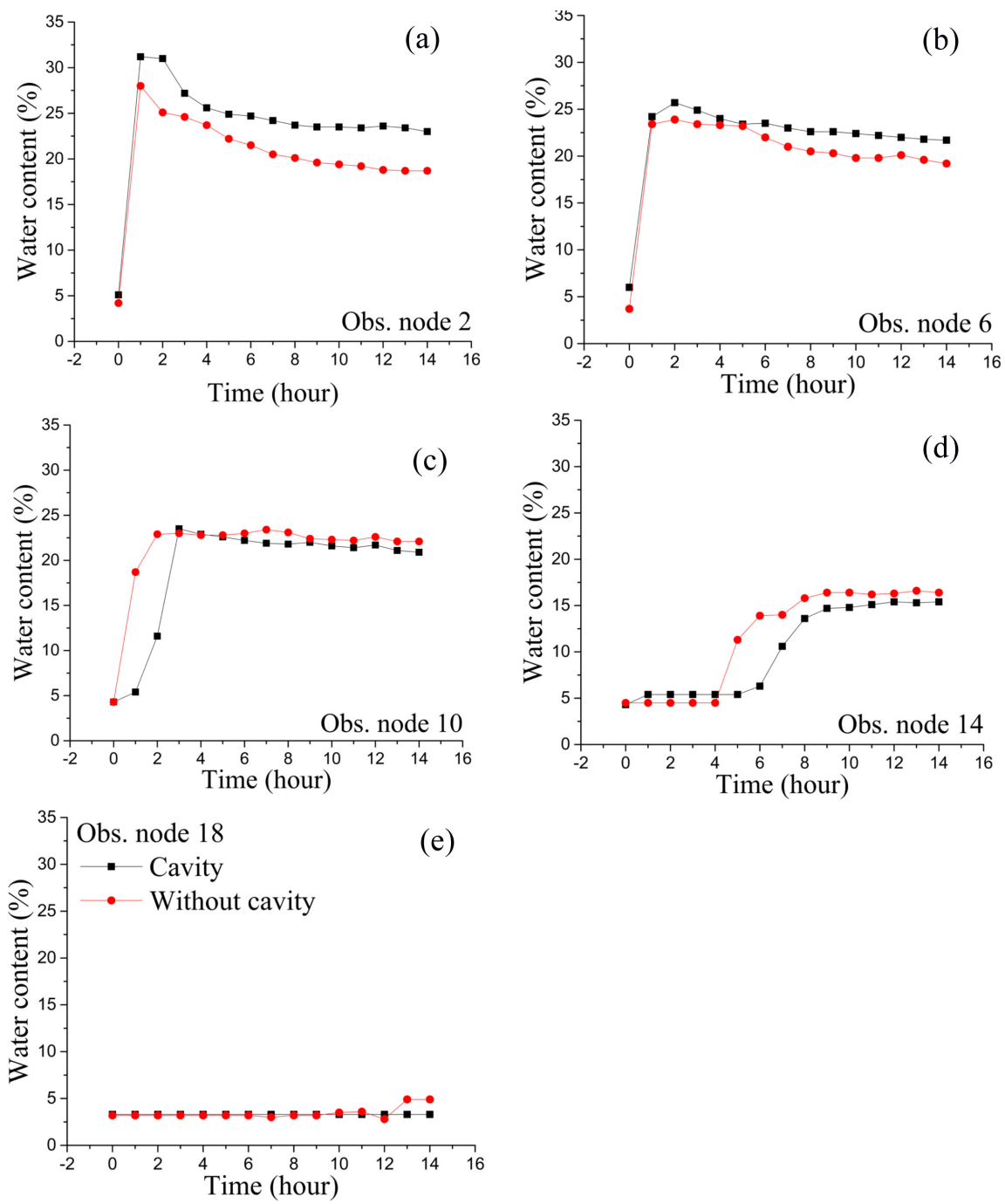

Figure 6. Comparison of water content of observation probes in vertical transect 2 near the cavity loess with and without applying cavity soil columns during 14 hours.

dropped down gradually after they reached the maximum value of $34 \%$ and $28 \%$ for the soil columns with and without loess cavity, respectively (Figure 6). Based on the presented curves, the WCs of applying loess cavity soil column in the upper layer (Layer I) and the middle layer (Layer II) (i.e. the observation probes at $28 \mathrm{~cm}$ and $30 \mathrm{~cm}$ cross section) was higher than those without applying loess cavity (Figure 6(a) \& Figure 6(b)) and remains these states until the termination of experimental process. However, the WCs at the deep layer of without cavity soil column was initially rising remarkably for 4 hours after the starting the experiment, while those of cavity soil column was just increasing at one hour later (Figure 6(d)). Interestingly, it was found that the water distribution of without cavity column reached the deep layer (i.e. $78-\mathrm{cm} \mathrm{depth)} \mathrm{at} 10$ hours of experiment (Figure 6(e)). In contrast, remarkably, the WCs of cavity soil column in the horizontal $78-\mathrm{cm}$ intersect did not change, even at the termination of experiment (Figure 6(e)). 

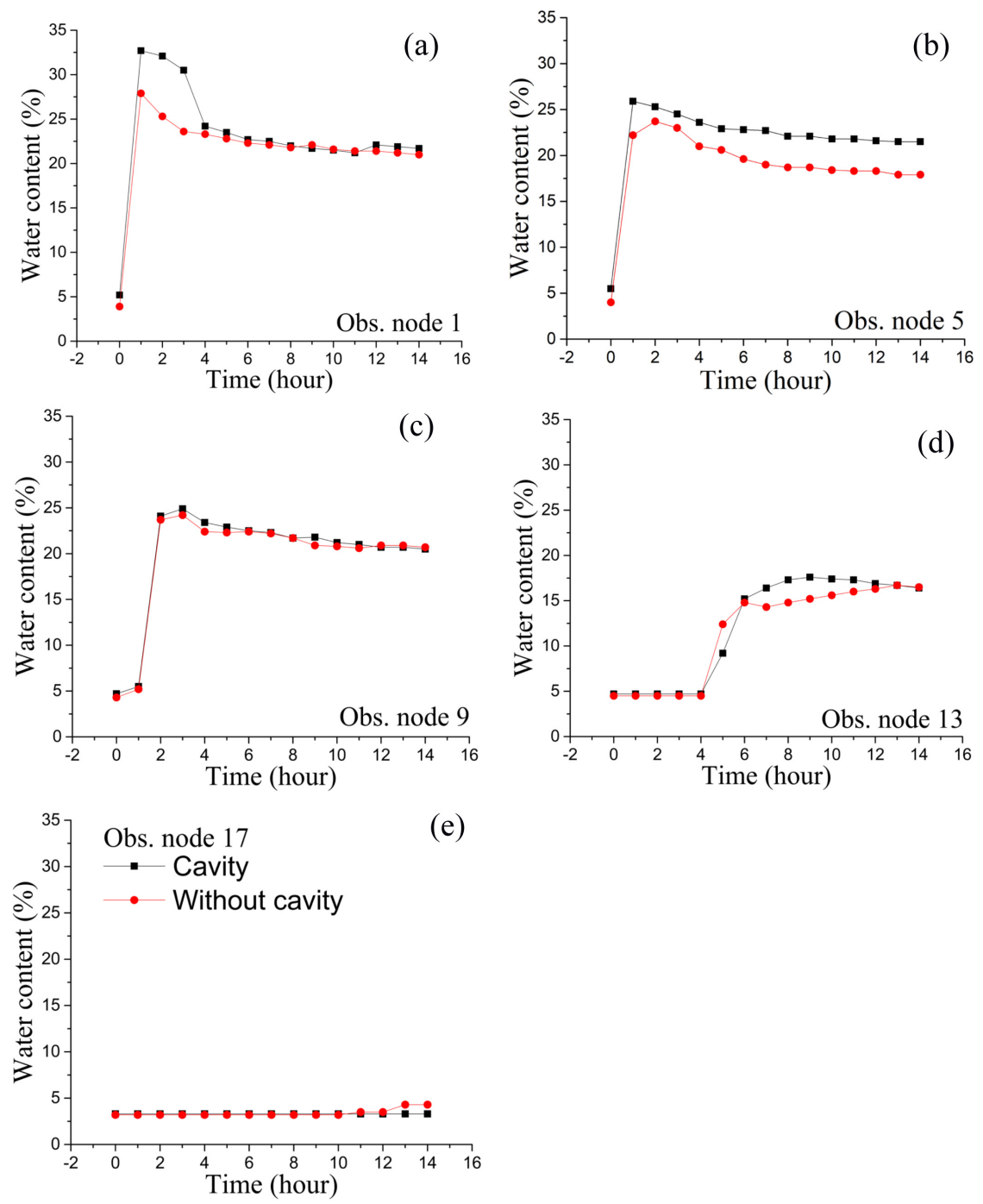

Figure 7. Comparison of water content of probes in vertical transect 1 with and without applying cavity soil columns during 14 hours.

Figures 7(a)-(e) also shows the comparison of water contents with and without applying cavity soil columns but for vertical transect 1 . There were no significant variations of water distributions of both soil columns. As shown in Figure 7 (a) \& Figure 7(b), some minor differences found at observation node 1 and 5 which the WC at observation node 1 was increased rapidly reached the maximum value of $32.7 \%$ and declined to nearly the same trend as the WCs of without cavity column at 3 hours later. The WCs of the observation node 5 and 9 at 46 and $62 \mathrm{~cm}$ deep, respectively, had the similar values from the beginning until the end of experiment process (Figure 7(c) \& Figure 7(d)). Furthermore, Figure 7(e) also shows the last two hours of experiment, the WCs slightly increase for the observation node 17 of without cavity soil column, and remain constant for those of applying cavity soil column as the consequences of loess cavity.

Comparison of water content at vertical transect 1 and transect 2 of soil col- 
umns with and without applying cavity at 14 hours is shown in Figure 8 (a) \& Figure 8(b). Figure 8(a) which represented the vertical cross section oriented at $18 \mathrm{~cm}$ from loess cavity showed that WCs of both soil columns at $14-\mathrm{cm}$ depth were about $21 \%$. But the WC of soil column without cavity at $30-\mathrm{cm}$ depth was decreased to $17.9 \%$, while those with cavity was gradually decreased to $21.5 \%$. It was noticeably that the WCs distribution at the deep layer had the similar trend for both soil columns at the end of infiltration process. Other comparison of WCs of that both soil column demonstrated the water distributions of vertical $37-\mathrm{cm}$ transect oriented closed to the loess cavity. It was interestingly found that the shallow depth of soil column with loess cavity had soil water much more than those without loess cavity and at the depth of $44 \mathrm{~cm}$ down both soil columns have nearly the same water content value (column 2 which is the nearest to the loess cavity). WCs' values of subsurface soil with applying loess cavity measured at 14 - and $30-\mathrm{cm}$ depth were $23 \%$ and $21.1 \%$ higher than those without loess cavity which at the same depth had WCs' values of $18.7 \%$ and $19.2 \%$. However, WCs of soil column without cavity was slightly higher than those with cavity and they had the similar trend.

\subsection{Comparisons of Model Simulation}

The single-porosity model of van Genuchten-Mualem was chose to determined soil hydraulic parameters by using HYDRUS-2D/3D Rosite for soil water retention and conductivity curves (Table 1 ). Noticeably, the saturated zone of ponded infiltration is not fully filled with water due to the entrapped air [56]. Figure 9 shows the observed and simulated water contents (WCs) for different depths, obtained by HYDRUS-2D/3D, for probes in vertical transect 2 closed to the cavity in the function of time as well as the associated scatter plots. The comparison between measured and simulated values of WCs with the determination coefficient (R2) in Figure 9 also showed that HYDRUS-2D/3D simulated WCs matched the corresponding observed results reasonably well for shallow surface layer which indicated a similar trend during the water infiltration process (i.e., in the depth of $30 \mathrm{~cm}$ ). It can be found that the HYDRUS model has described the WCs adequately for the upper and middle layer which had a good determination

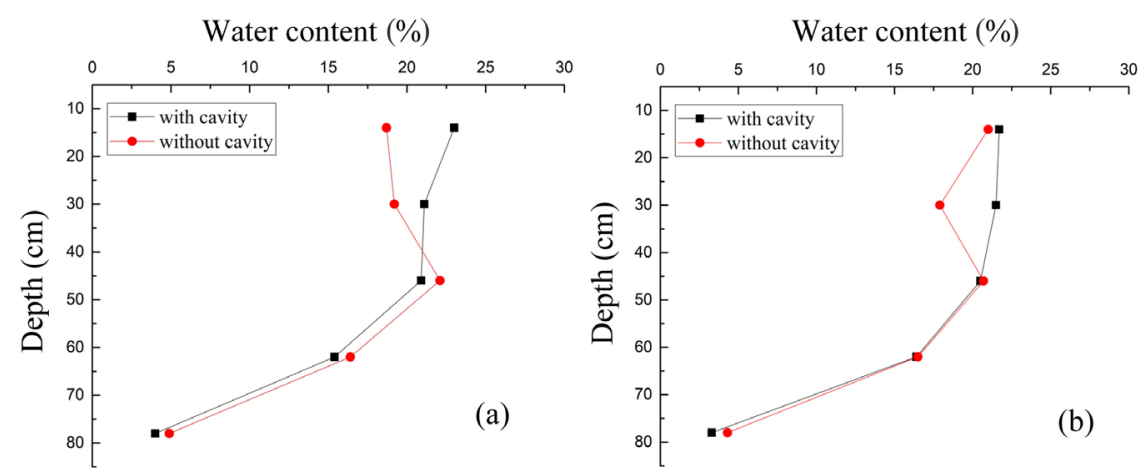

Figure 8. Comparison of water content at vertical transect 1 and 2 of soil columns with and without applying loess cavity at 14 hours. 
Table 1. Soil hydraulic parameters determined by the van Genuchten of HYDRUS rosite.

\begin{tabular}{ccccccccc}
\hline Depth (cm) & Soil layer & $\theta_{r}$ & $\theta_{s}$ & $\alpha\left(\mathrm{cm}^{-1}\right)$ & $n$ & $K_{s}\left(\mathrm{~cm} \cdot \mathrm{h}^{-1}\right)$ & $I$ & $\mathrm{BD}\left(\mathrm{g} \cdot \mathrm{cm}^{-3}\right)^{\mathrm{a}}$ \\
\hline $0-28$ & 1 & 0.03 & 0.34 & 0.0065 & 1.5819 & 1.376 & 0.5 & 1.15 \\
$28-51$ & 2 & 0.03 & 0.26 & 0.0064 & 1.5874 & 0.741 & 0.5 & 1.29 \\
$51-100$ & 3 & 0.03 & 0.18 & 0.0065 & 1.5858 & 1.014 & 0.5 & 1.22 \\
\hline
\end{tabular}

${ }^{\mathrm{a}} \mathrm{BD}$ is bulk density.

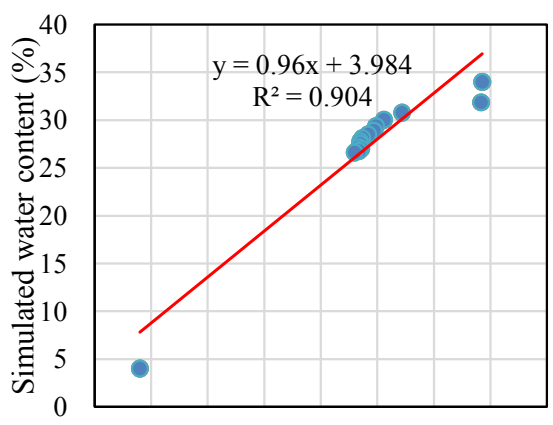

(a)

$\begin{array}{lllllllll}0 & 5 & 10 & 15 & 20 & 25 & 30 & 35 & 40\end{array}$

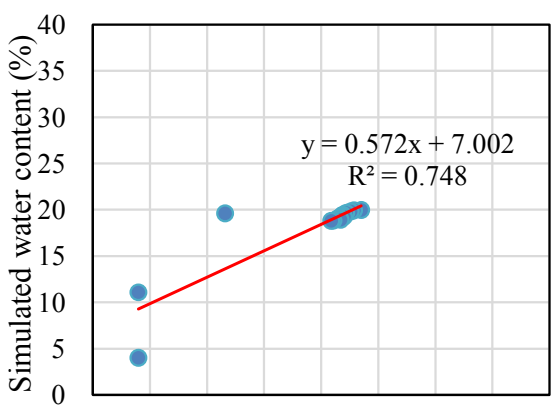

(c)

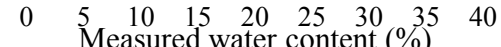

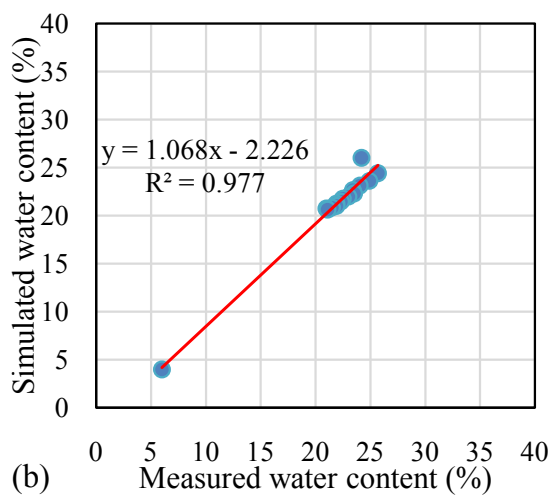

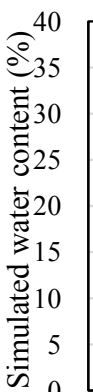

(d)

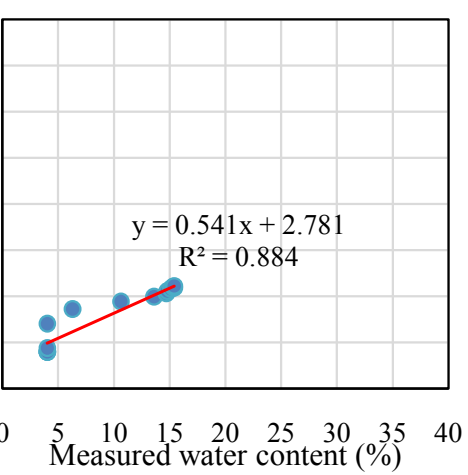

Figure 9. Comparison of simulated water content by HYDRUS-2D/3D with observed result during 14 hours.

coefficients (R2) of $0.90,0.977$, and 0.88. Except for the deep layer of experimental process, the model slightly underestimated volumetric water content. In this period, the correlation coefficient was 0.74 for the probes 13 and 14 at depth $62 \mathrm{~cm}$ in the deep layer. Furthermore, the determination coefficients variably ranged from 0.88 to 0.97 across different probe positions, representing the good predictive capability of the HYDRUS-2D/3D at the shallow layer.

As shown by the criteria indices for the efficiency of the model performance, the comparison between measured and simulated results were expressed in terms of RMSE, EF, and NRMSE, demonstrated in Table 2. The RMSE values describing the differences between measured and simulated WCs were 3.63 for $14 \mathrm{~cm}$ depth, 1.07 for $30 \mathrm{~cm}$ depth, 3.63 for $46 \mathrm{~cm}$ depth, 3.05 for $62 \mathrm{~cm}$ depth, and 0.22 for $78 \mathrm{~cm}$ depth. Despite an overestimation in $62 \mathrm{~cm}$ depth $($ NRMSE $=$ $31.59 \%)$, the EF values, ranging from $0.64-0.94$, where a value of 1 would mean the model perfectly simulated the data, indicated that the simulated WCs had a 
Table 2. Statistical analysis of HYDRUS model performance comparing to the measured results. RMSE, EF, and NRMSE are the root water squared and model efficiency coefficient, respectively.

\begin{tabular}{cccc}
\hline Variable & RMSE & EF & NRMSE \\
\hline Water content $\left(\mathrm{cm}^{3} \cdot \mathrm{cm}^{-3}\right)$ & & & \\
$14 \mathrm{~cm}$ depth & 3.63 & 0.68 & 15 \\
$30 \mathrm{~cm}$ depth & 1.07 & 0.94 & 4.93 \\
$46 \mathrm{~cm}$ depth & 3.63 & 0.67 & 19.23 \\
$62 \mathrm{~cm}$ depth & 3.05 & 0.64 & 31.59 \\
$78 \mathrm{~cm}$ depth & 0.22 & & 5.63 \\
Water front $(\mathrm{cm})$ & & & \\
2 hours & 6.94 & -16.24 & 15.61 \\
4 hours & 2.62 & 0.06 & 4.73 \\
6 hours & 1.88 & 0.5 & 3.04 \\
8 hours & 1.6 & 0.64 & 2.45 \\
10 hours & 1.72 & 0.61 & 2.52 \\
12 hours & 1.87 & 0.54 & 2.64 \\
14 hours & 2.72 & & 3.76 \\
Cumulative infiltration $(\mathrm{cm})$ & 3.44 & 0.848 & 5.86 \\
Infiltration rate $\left(\mathrm{cm} \cdot \mathrm{min}^{-2}\right)$ & 0.026 & 0.9 & 16.24 \\
\hline
\end{tabular}

good agreement with the measured values for all WCs depths during the experimental process.

Figure 10(a) indicates the comparison of measured infiltration rate with those simulated by HYDRUS-2D/3D. This model simulation was capable of capturing the temporal trend of water fronts for all soil depths. The variations of water fronts were mainly to different soil bulk density as well as the percolation. The simulation results of HYDRUS model with van Genuchten-Mualem shows a best agreement with measured results which had the coefficient of determination (R2) about 0.98 . The model performance of HYDRUS-2D/3D was quantified by the root mean square error (RMSE), the efficiency coefficient (EF), and the normalized root square error (NRMSE) and their values were listed in Table 2. As the evident in Table 2, the criteria indices were 0.026 for RMSE, 16.24 for NRMSE, and 0.9 for EF. Figure 10(b) demonstrates the comparison of simulated and measured cumulative infiltration. It was found that the simulated results by HYDRUS-2D/3D are larger than the measured results at $120 \mathrm{~min}$ and then their trends gradually came closer until the termination of infiltration process. As an inspection of Figure 10(b), in general, the simulated cumulative infiltration was in good agreement with the measured results, especially, at the deep surface. The criteria indices were 3.44 for RMSE, 5.86 for NRMSE, and 0.848 for EF (Table 2). These means that the HYDRUS-2D/3D-simulated infiltration rate and cumulative infiltration agreed well with the measured values.

Figure 11 demonstrates the comparison of simulated and measured WF of the soil column with loess cavity at every two hours. Obviously, the WF simulated by HYDRUS-2D/3D at 2 hours after starting was deeper, inversely, they both approached the similar trend at 4 hours later. It is interesting to note that at 

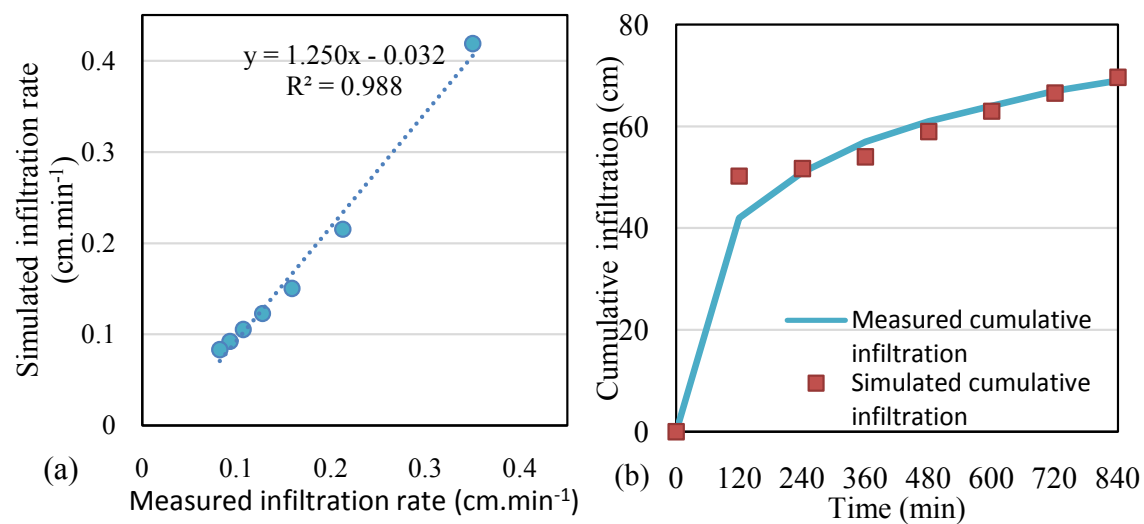

Figure 10. Comparison between HYDRUS-2D/3D and observed results: (a) infiltration rate, and (b) cumulative infiltration.

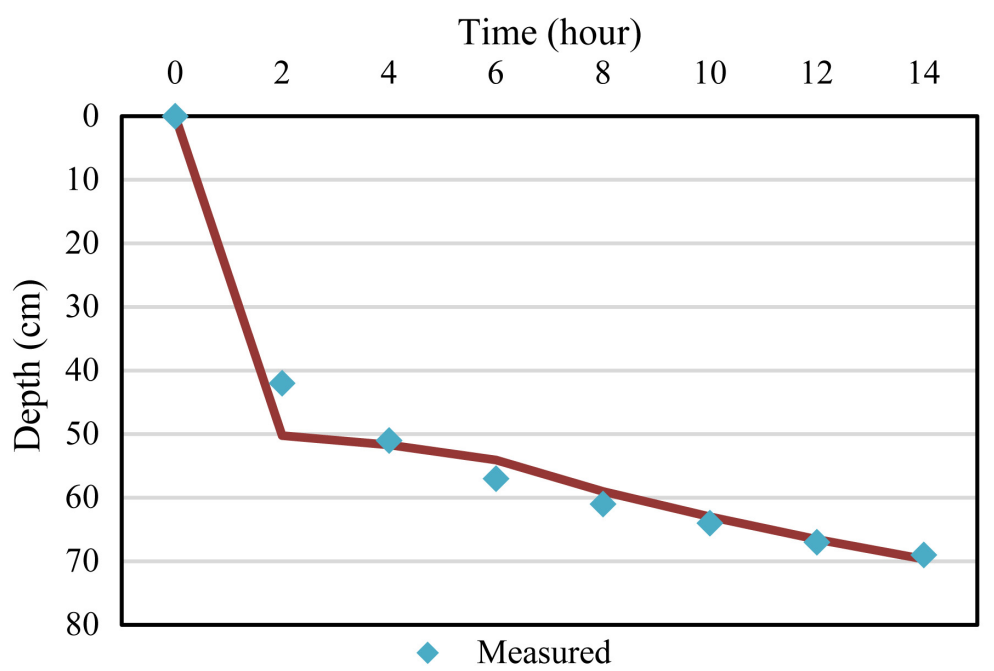

Figure 11. Comparison of simulated and measured wetting front of the soil column with loess cavity at every two hours.

the termination of infiltration experiment, the measured and simulated advancing wetting depth approached the similar values of 69 and $69.66 \mathrm{~cm}$, respectively. As seen in Table 2, the values of RMSE, EF, and NRMSE of simulated WF at 2 hours were $6.94,-16.24$, and 15.61 , respectively, which mean that the model simulation was overestimated the WF at the commencement of the infiltration process. Whereas, the simulated water fronts after 2 hours of infiltration process were capable to measured results. The RMSE values ranged from 2.62 to 1.6, while the NRMSE ranged from $3.76 \%$ to $4.73 \%$, and EF values ranged from 0.06 to 0.64 . However, in general, the simulated and measured WFs are fitting well together.

The HYDRUS-2D/3D model was used to investigate the water distribution in soil column with loess cavity for comparing to the experimental results. Figure 12 shows the spatial distributions of water contents in every two hours. As the evident of Table 2, the root mean square errors (RMSE) correspond to 6.94, $2.62,1.88,1.6,1.72,1.87$, and 2.72 between the simulated and measured water 


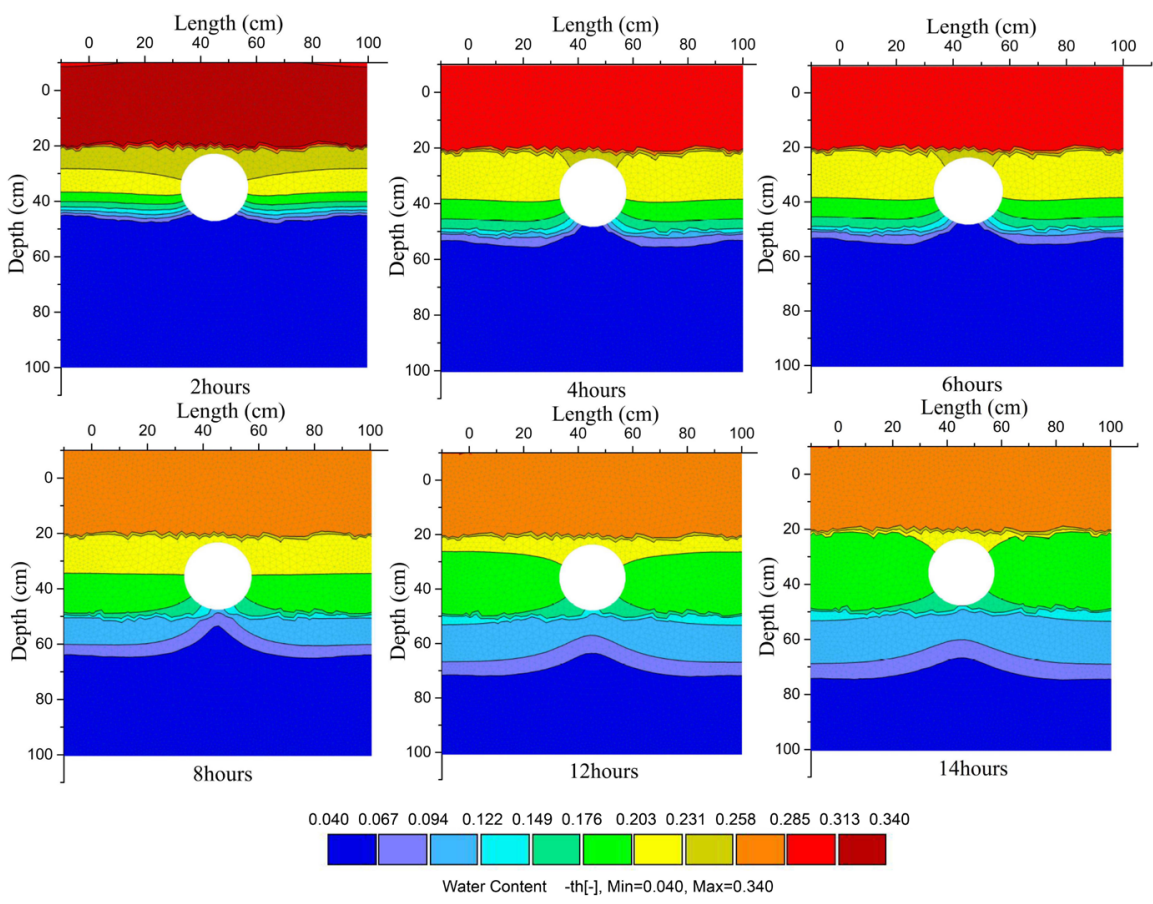

Figure 12. Simulated 2D spatial distribution of water content in every two hours.

front at $2,4,6,8,10,12$, and 14 hours, respectively. Those indicate the simulation seems to underestimate the water front at subsurface.

\section{Discussion}

\subsection{The Efficiency of Loess Cavity on Mitigating Soil Water Movement}

Soil water distribution is an important key factor for hydrologic cycle in subsurface root water uptake. Especially, in Chinese Loess Plateau where is challenging a serious problems of soil erosion for many years long. The current study of water distribution in loess soil column with applying cavity loess by comparing the loess cavity efficiency to improve soil moisture in sublayer soil to the soil column without loess cavity shows that the WCs in subsurface of soil column with cavity was noticeably higher than those without cavity in Figure 4(a) \& Figure 4(b). As observed in Figure 4(c) \& Figure 4(e), WCs in soil column with cavity at deeper layer (i.e. 46-, 62-, and 78-cm depth) were more less than those without cavity when the water movement permeated through the loess cavity. As the consequences of loess cavity, the water infiltrative rate in soil column with cavity was also gradually reduced after the water infiltrated through the loess cavity in Figure 8. Those results greatly agree with the previous studies which found that the cavity-making technique improved water storage at the root water uptake layer of crops and reduced deep water infiltration [19]. The current study shows that the loess cavity modified the soil structure by strengthening the capillary action of soil layer above the loess cavity and surrounding. It was deemed the loess cavity was reducing the gravity force and disturbed the infiltration process when 
water was moving across. Within these, the soil moisture in subsurface of soil column with cavity was ameliorated.

\subsection{HYDRUS 2D/3D Performance in Applying Loess Cavity on Soil Column}

To be better make economic benefits and save time of doing experiment, the HYDRUS model was applied in this current study. HYDRUS-2D/3D was utilized for comparing the experimental results to its simulations. A three-layer soil domain with different soil hydraulic parameters was defined in the model. The agreement between measured and simulated WCs in soil column with loess cavity scenario was quantitatively evaluated using the RMSE, EF, and NRMSE criteria indices (Table 2). As shown in Figure 9(c) \& Figure 9(d), the WCs at deep layer seems to be slightly underestimated by the HYDRUS model. These discrepancies can be somewhat explained by the representation of the heterogeneous soil in the HYDRUS model. While soil hydraulic parameters and soil texture typically vary gradually in the soil profile [57]. In general, the measured results were known to be effected by the heterogeneity [58]. On account of the statistical coefficients $(\mathrm{RMSE}=0.5-1.9$ for first two layers, and RMSE $=0.6-2$ for the bottom layer), despite a slight overestimation, the simulated results agreed well with the measured values for the first 2 layers and fairly agreed for the deep layer. This agreed with the previous study of the spatial and temporal prediction of soil moisture dynamic which found that the HYDRUS model is more capable of simulating the rapid variation of the surface soil moisture dynamics than the slower deeper-profile variations [59]. However, the mean EF for the WCs comparison was 0.73 , which indicates that the efficiency of the model simulation was good [60].

In our current study, it can be found that the simulation of water fronts from four hours of commencement of infiltration process was better modelled than the two hours' water front (Figure 11). It is very interesting to note that the HYDRUS-2D/3D model slightly overestimates the depth of advancing wetting front (Figure 11). As shown in Figure 9, the simulated water storage at the first two hours of was more less than those of measured values. Based on the law of conservation of mass, under the equivalent condition of the cumulative infiltration, the larger water holding capacity that the soil layer has, the smaller advancing depth that the WF can permeate [61]. Consequently, the depth of advancing wetting front simulated by HYDRUS-2D/3D moved faster at first two hours.

As observed in the result sections, the disparity between observed and simulated results is likely triggered by two groups: 1) the property of some materials was not considered in the simulations because of absent observation data. For example, the anisotropy of the hydraulic conductivity and the hysteresis of the soil hydrological functions of used materials were not evaluated; 2) the definition of boundary condition in HYDRUS model was not well fitted with the ex- 
perimental design, since two-dimensional simulations are insufficient to solve such condition because they suppose constant conditions in the third dimension. The soil column with cavity as distinct three-dimensional individuals demand three-dimensional apparent illustration.

\section{Conclusions}

The paper aims to advance our current understandings of soil moisture storage in subsurface and water infiltration rate in loess soil. A conducted infiltration experiment in two three-layered soil columns presents the efficiency of cavity technique on ameliorating the soil moisture at the shallow surface and to investigate the validity of the proposed model. The experimental data show that the loess cavity had affected on soil water dynamic by decreasing the infiltration rate when the flux was going across the loess cavity. In addition, it also affected the WFs since it made the water permeated into the soil surface steadily that made to improve the soil moisture at the shallow soil layer. The fitting of experimental data indicated that the measured infiltration rate, water content, and waterfront were all well described by power-law functions of the infiltration time.

The model results showed that the simulated infiltration rate, water content, and water fronts were in good agreement with corresponding measured values, indicating that the model represented good accurately with experimental results. However, a few discrepancies were found in the model's performance, and we identified two potential causes that contributed to these discrepancies. First, the boundary condition of loess cavity defined as seepage condition is somewhat made much water infiltrated into it and likely made HYDRUS-2D/3D underestimate this condition. Second, the neglecting of preferential flow may be expected when assuming constant soil hydraulic parameters through the simulation process while dynamic changes in hydraulic properties may have occurred as a result of wetting and drying cycles. Third, 2D domain of HYDRUS model seems to be not every well fitted with the real infiltration domain, since the cavity using in the infiltration experiment was a half-sphere basket and HYDRUS model defined the loess cavity as an empty circle.

This study has, however, certain limitations, as it is in the early first stage of the development of loess cavity method. The experiment of this study was just conducted on the loess soil profile scale. A range of flow types was ignored during the procedure. Furthermore, the evaporation was neglected, because this study was taking in winter. Following the above discussion section, further research of improvement of loess cavity method should be focused on: 1) the size and number of loess cavity applying on soil column which absolutely affected on the soil water dynamic; 2) applying this method on the field study; 3) conducting the experiment in different soil types and land use; 4) applying in different irrigation method like drip irrigation, sprinkler etc. Therefore, more experiments are recommended to be better understanding the efficiency of loess cavity method under different initial conditions. And the 3D domain of HYDRUS model 
is strongly recommended for the future research.

\section{Acknowledgements}

The authors are deeply grateful to Dr. Xianwen $\mathrm{Li}$, College of Water Resources and Architectural Engineering and Dr. Hu Yaxian, Institute of Soil and Water Conservation, Northwest A\&F University, Shaanxi, Yangling, for their kind help and enthusiasm in guiding this $r$ study from conception to its completion. The author would like to thank the China Scholarship Council (CSC) for the financial support. The authors are also grateful to Mr. Saleh Shahriar, College of Economics and Management, Northwest A\&F university, for his assistance and comments on an earlier draft of the paper.

\section{Funding}

This research was funded by the National Natural Science Foundation of China [grant numbers 51179160].

\section{Conflicts of Interest}

The authors declare no conflict of interest.

\section{References}

[1] Fu, B. (1989) Soil Erosion and Its Control in the Loess Plateau of China. Soil Use and Management, 5, 76-82. https://doi.org/10.1111/j.1475-2743.1989.tb00765.x

[2] Cai, Q.G. (2001) Soil Erosion and Management on the Loess Plateau. Journal of Geographical Sciences, 11, 53-70. https://doi.org/10.1007/BF02837376

[3] Hui, S. and Shao, M. (2000) Soil and Water Loss from the Loess Plateau in China. Journal of Arid Environments, 45, 9-20. https://doi.org/10.1006/jare.1999.0618

[4] Ritsema, C.J. (2003) Introduction: Soil Erosion and Participatory Land Use Planning on the Loess Plateau in China. Catena, 54, 1-5. https://doi.org/10.1016/S0341-8162(03)00052-3

[5] Zhang, Q., et al. (2009) Effects of Land Use on Soil Quality on the Loess Plateau in Northwest Shanxi Province. In: Computer and Computing Technologies in Agriculture II, Volume 1, Springer US, Boston.

[6] Yi, L. and Shao, M. (2007) Experimental Study on Influence Factors of Rainfall and Infiltration under Artificial Grassland Coverage. Transactions of the Chinese Society of Agricultural Engineering, 23, 18-23.

[7] He, B., et al. (2015) Dynamic Response of Satellite-Derived Vegetation Growth to Climate Change in the Three North Shelter Forest Region in China. Remote Sensing, 7, 9998-10016. https://doi.org/10.3390/rs70809998

[8] Qu, B., et al. (2015) Spatio-Temporal Changes in Vegetation Activity and Its Driving Factors During the Growing Season in China from 1982 to 2011. Remote Sensing, 7, 13729-13752. https://doi.org/10.3390/rs71013729

[9] Yao, Z., et al. (2016) Multiple Afforestation Programs Accelerate the Greenness in the "Three North" Region of China from 1982 to 2013. Ecological Indicators, 61, 404-412. https://doi.org/10.1016/j.ecolind.2015.09.041

[10] Chen, N., Ma, T. and Zhang, X. (2016) Responses of Soil Erosion Processes to Land 
Cover Changes in the Loess Plateau of China: A Case Study on the Beiluo River Basin. Catena, 136, 118-127. https://doi.org/10.1016/j.catena.2015.02.022

[11] Yan, R., et al. (2016) Topographical Distribution Characteristics of Vegetation Restoration in the Beiluo River Basin from 1995 to 2014. Journal of Northeastern University Nature Science, 37, 1598-1603.

[12] Cao, S., et al. (2016) Ecosystem Water Imbalances Created during Ecological Restoration by Afforestation in China, and Lessons for Other Developing Countries. Journal of Environmental Management, 183, 843-849. https://doi.org/10.1016/j.jenvman.2016.07.096

[13] Lei, D., et al. (2016) Severe Depletion of Soil Moisture Following Land-Use Changes for Ecological Restoration: Evidence from Northern China. Forest Ecology Management, 366, 1-10. https://doi.org/10.1016/j.foreco.2016.01.026

[14] Jia, X., et al. (2017) Soil Moisture Decline Due to Afforestation across the Loess Plateau, China. Journal of Hydrology, 546, 113-122. https://doi.org/10.1016/j.jhydrol.2017.01.011

[15] Dang, J.Q., et al. (2001) Improving Soil Moisture-Holding Capacity Using Cavity-Making by Explosion in the Loess Plateau. Transactions of the Chinese Society of Agricultural Engineering, 17, 161-164.

[16] Yan, B.W., Dang, J.Q. and Zhang, R.H. (2005) Research on the Restrain Effective on Soil-Water Evaporation of the Technology of Cavity-Making by Explode in Farmland. Water Saving Irrigation, 6, 8-10.

[17] Dang, J.Q., et al. (2002) Application of Cavity-Making by Explosion in Arid-Agriculture. Journal of Hydraulic Engineering, 33, 103-106.

[18] Dang, J.Q., et al. (2002) Experiment on Technique of Cavity Making by Explosion in Agriculture. Journal of Northwest Sci-Tech University of Agriculture, 30, 174-176.

[19] Dang, J.Q., et al. (2002) Application of Cavity-Making by Explosion in Arid-Agriculture. Journal of Hydraulic Engineering, 10, 103-106.

[20] Van Dam, J.C., et al. (1997) Theory of Swap Version 2.0; Simulation of Water Flow, Solute Transport and Plant Growth in the Soil-Water-Atmosphere-Plant Environment. DLO Win and Staring Centre, Wageningen, 287-295.

[21] Douglasmankin, K.R., Srinivasan, R. and Arnold, J.G. (2010) Soil and Water Assessment Tool (Swat) Model: Current Developments and Applications. American Society of Agricultural and Biological Engineers, 53, 1423-1431.

[22] Fernández, J.E., et al. (2002) Simulating the Fate of Water in a Soil-Crop System of a Semi-Arid Mediterranean Area with the Wave 2.1 and the Euro-Access-Ii Models. Agricultural Water Management, 56, 113-129. https://doi.org/10.1016/S0378-3774(02)00009-4

[23] Ghosh, R.K. and Maity, S.P. (1976) Influence of Antecedent Moisture on Infiltration of Water into Soils (in Situ). Soil Science Society of America Journal, 122, 124-125. https://doi.org/10.1097/00010694-197608000-00009

[24] Liu, X., et al. (2005) Scs Model Based on Geographic Information and Its Application to Simulate Rainfall-Runoff Relationship at Typical Small Watershed Level in Loess Plateau. Transactions of the Chinese Society of Agricultural Engineering, 21, 93-97.

[25] Nishat, S., Guo, Y. and Baetz, B.W. (2007) Development of a Simplified Continuous Simulation Model for Investigating Long-Term Soil Moisture Fluctuations. Agricultural Water Management, 92, 53-63. https://doi.org/10.1016/j.agwat.2007.04.012

[26] Wang, et al. (1999) Modified Green and Ampt Models for Layers Soil Infiltration 
and Muddy Water Infiltration. Soil Science Society of America Journal, 164, 445-453. https://doi.org/10.1097/00010694-199907000-00001

[27] Cooley, R.L. (1983) Some New Procedures for Numerical Solution of Variably Saturated Flow Problems. Water Resources Research, 19, 1271-1285. https://doi.org/10.1029/WR019i005p01271

[28] Huyakorn, P.S., et al. (1986) A Three-Dimensional Finite-Element Model for Simulating Water Flow in Variably Saturated Porous Media. Water Resources Research, 22, 1790-1808. https://doi.org/10.1029/WR022i013p01790

[29] Neuman, S.P. (1973) Saturated-Unsaturated Seepage by Finite Elements. Journal of the Hydraulics Division, 99, 2233-2250.

[30] Kumar, S., Sharma, P.K. and Hari Prasad, K.S. (2014) Modeling of Unsaturated Flow Using Hydrus Software. Race-2014, Paper ID: 1434.

[31] Richards, A.L. (1931) Capillary Conduction of Liquids in Porous Mediums. Physics, 1, 318-333. https://doi.org/10.1063/1.1745010

[32] Arampatzis, G., et al. (2001) Estimation of Unsaturated Flow in Layered Soils with the Finite Control Volume Method. Irrigation \& Drainage, 50, 349-358. https://doi.org/10.1002/ird.31

[33] Simunek, J., Genuchten, M.T.V. and Šejna, M. (2005) The Hydrus-1d Software Package for Simulating the Movement of Water, Heat, and Multiple Solutes in Variably Saturated Media, Version 3.0.

[34] Karandish, F. and Šimůnek, J. (2016) A Comparison of Numerical and Machine-Learning Modeling of Soil Water Content with Limited Input Data. Journal of Hydrology, 543, 892-909. https://doi.org/10.1016/j.jhydrol.2016.11.007

[35] Tafteh, A. and Sepaskhah, A.R. (2012) Application of Hydrus-1d Model for Simulating Water and Nitrate Leaching from Continuous and Alternate Furrow Irrigated Rapeseed and Maize Fields. Agricultural Water Management, 113, 19-29. https://doi.org/10.1016/j.agwat.2012.06.011

[36] Karandish, F. and Darzi-Naftchali, A. (2017) Application of Hydrus (2d/3d) for Predicting the Influence of Subsurface Drainage on Soil Water Dynamics in a Rainfed-Canola Cropping System. Irrigation and Drainage, 67, 29-39.

[37] Li, X., et al. (2015) Modeling Soil Water Dynamics in a Drip-Irrigated Intercropping Field under Plastic Mulch. Irrigation Science, 33, 289-302. https://doi.org/10.1007/s00271-015-0466-4

[38] Mashayekhi, P., et al. (2016) Different Scenarios for Inverse Estimation of Soil Hydraulic Parameters from Double-Ring Infiltrometer Data Using Hydrus-2d/3d. International Agrophysics, 30, 203-210. https://doi.org/10.1515/intag-2015-0087

[39] Sasidharan, S., et al. (2018) Evaluating Drywells for Stormwater Management and Enhanced Aquifer Recharge. Advances in Water Resources, 116, 167-177. https://doi.org/10.1016/j.advwatres.2018.04.003

[40] Simunek, J., et al. (2017) Vadose Zone Fate and Transport Simulation of Chemicals Associated with Coal Seam Gas Extraction. AGU Fall Meeting.

[41] Weiss, T., Dahan, O. and Turkeltub, T. (2015) Numerical Model of Water Flow and Solute Accumulation in Vertisols Using Hydrus 2d/3d Code. EGU General Assembly Conference.

[42] El-Nesr, M.N., Alazba, A.A. and Šimůnek, J. (2014) Hydrus Simulations of the Effects of Dual-Drip Subsurface Irrigation and a Physical Barrier on Water Movement and Solute Transport in Soils. Irrigation Science, 32, 111-125.

https://doi.org/10.1007/s00271-013-0417-x 
[43] Wang, C., Mao, X. and Hatano, R. (2014) Modeling Ponded Infiltration in Fine Textured Soils with Coarse Interlayer. Soil Science Society of America Journal, 78, 745-753. https://doi.org/10.2136/sssaj2013.12.0535

[44] Šimůnek, J., Genuchten, M.T.V. and Šejna, M. (2016) Recent Developments and Applications of the Hydrus Computer Software Packages. Vadose Zone Journal, 6.

[45] Simunek, J. (2008) Development and Applications of the Hydrus and Stanmod Software Packages, and Related Codes. Vadose Zone Journal, 72, 587-600. https://doi.org/10.2136/vzj2007.0077

[46] Šim, J., van Genuchten, M.T. and Šejna, M. (1999) The Hydrus-2d Software Package for Simulating the Two-Dimensional Movement of Water, Heat, and Multiple Solutes in Variably-Saturated Media: Version 2.0. Colorado School of Mines.

[47] Šimůnek, J., Van Genuchten, M.T. and Šejna, M. (2006) The Hydrus Software Package for Simulating Two- and Three-Dimensional Movement of Water, Heat, and Multiple Solutes in Variably-Saturated Media. Technical Manual, Version, 1, 241.

[48] Van Genuchten, M.T. (1980) A Closed-Form Equation for Predicting the Hydraulic Conductivity of Unsaturated Soils 1. Soil Science Society of America Journal, 44, 892-898. https://doi.org/10.2136/sssaj1980.03615995004400050002x

[49] Mualem, Y. (1976) A New Model for Predicting the Hydraulic Conductivity of Unsaturated Porous Media. Water Resources Research, 12, 513-522. https://doi.org/10.1029/WR012i003p00513

[50] Neuman, S.P. (1976) Wetting Front Pressure Head in the Infiltration Model of Green and Ampt. Water Resources Research, 12, 564-566. https://doi.org/10.1029/WR012i003p00564

[51] Ebrahimian, H., et al. (2012) Comparison of One- and Two-Dimensional Models to Simulate Alternate and Conventional Furrow Fertigation. Journal of Irrigation \& Drainage Engineering, 138, 929-938. https://doi.org/10.1061/(ASCE)IR.1943-4774.0000482

[52] Schaap, M.G., Leij, F.J. and Genuchten, M.T.V. (2001) Rosetta: A Computer Program for Estimating Soil Hydraulic Parameters with Hierarchical Pedotransfer Functions. Journal of Hydrology, 251, 163-176. https://doi.org/10.1016/S0022-1694(01)00466-8

[53] Weik, M.H. (2001) Root-Mean-Square Deviation, in Computer Science and Communications Dictionary. Springer US, Boston, 1501. https://doi.org/10.1007/1-4020-0613-6

[54] Nash, J.E. (1970) River Flow Forecasting through Conceptual Models. Part 1-a Discussion of Principles. Journal of Hydrology, 10, 282-290. https://doi.org/10.1016/0022-1694(70)90255-6

[55] Bannayan, M. and Hoogenboom, G. (2009) Using Pattern Recognition for Estimating Cultivar Coefficients of a Crop Simulation Model. Field Crops Research, 111, 290-302. https://doi.org/10.1016/j.fcr.2009.01.007

[56] Hammecker, C., et al. (2010) Experimental and Numerical Study of Water Flow in Soil under Irrigation in Northern Senegal: Evidence of Air Entrapment. European Journal of Soil Science, 54, 491-503. https://doi.org/10.1046/j.1365-2389.2003.00482.x

[57] Tan, X., et al. (2015) Field Analysis of Water and Nitrogen Fate in Lowland Paddy Fields under Different Water Managements Using Hydrus-1d. Agricultural Water Management, 150, 67-80. https://doi.org/10.1016/j.agwat.2014.12.005

[58] Weihermüller, L., Kasteel, R. and Vereecken, H. (2006) Soil Heterogeneity Effects 
on Solute Breakthrough Sampled with Suction Cups. Vadose Zone Journal, 5, 886893. https://doi.org/10.2136/vzj2005.0105

[59] Chen, M., Willgoose, G.R. and Saco, P.M. (2014) Spatial Prediction of Temporal Soil Moisture Dynamics Using Hydrus-1d. Hydrological Processes, 28, 171-185. https://doi.org/10.1002/hyp.9518

[60] Krause, P., Boyle, D. and Bäse, F. (2005) Comparison of Different Efficiency Criteria for Hydrologic Models. Advances in Geosciences, 5, 89-97. https://doi.org/10.5194/adgeo-5-89-2005

[61] Ying, M., et al. (2010) Modeling Water Infiltration in a Large Layered Soil Column with a Modified Green-Ampt Model and Hydrus-1d. Computers Electronics in Agriculture, 71, S40-S47. 